\title{
A No-Budget, In-House, Staff-Led Professional Development Model
}

\section{By Jennifer King}

ABSTRACT: From September 2015 through January 2016, the staff of the Gelman Library Special Collections Research Center (SCRC) at The George Washington University $(\mathrm{GW})$ participated in a staff-designed and -led professional development discussion series. The group met four times and included both SCRC staff who had collection development responsibilities and those who had none. In addition, several librarians from outside of the SCRC joined the group. Participants read and discussed seminal articles about collection development, reviewed aspects of current collection development activities, and drafted a collection development policy template that is now used by all SCRC curatorial staff. Responses to a survey following the series as well as participants' informal comments indicated that the series met its stated goals. As of June 2016, the majority of the SCRC collecting areas had posted new collection development policies online using the template drafted by series participants. Furthermore, this series captured and focused the existing collaborative and collegial atmosphere in the GW libraries system and led to other partnerships and innovations.

\section{Introduction}

From September 2015 through January 2016, the Gelman Library Special Collections Research Center (SCRC) staff at The George Washington University (GW) engaged in a staff-designed and -led professional development discussion series. The series focused on collection development with discussions including both theoretical and practical components. The series design fully leveraged staff-held skills and collective interest and enthusiasm for professional growth. Highly effective and productive for the SCRC staff, the series inspired other library-wide in-house staff-directed professional growth opportunities.

The series' goals included: 1) consider and discuss aspects of current collection development activities as well as aspirations for future SCRC collection building; 2) identify, analyze, and critique current processes and tools; 3) generate ideas to improve these tools; and 4) support each other in this work.

\section{Literature Review}

Models described in the literature include all-staff days resembling conferences, professional development committees composed of library staff from various units with a mandate to attract library-wide audiences, and committees organized for a specific subset of library staff with a narrowly focused mandate to explore one aspect of their work. 
First held in 2005, the annual all-day staff development program at Penn State University, as described in the article "Leading Staff Development from the Bottom Up" by Ann MacKay Snowman, is structured as a conference with multiple concurrent sessions organized and presented by staff for staff. The professional development opportunities focus on attendees, but staff on ". . . the planning committee has other opportunities for development through their work with the Libraries' Public Relations and Marketing department, the Human Resources Office, the Business Office, and the Libraries' Information Technology Unit. ..." Through the years, the all-staff program evolved until, in 2012, the libraries hired a user services training coordinator as the first permanent member of the planning committee. In 2016, the local public library was invited to join the planning committee in an effort to advance the collaborative work of the public and university libraries in College Station. As an additional innovation in 2016, the sessions were recorded and shared with staff who did not work on the main campus.

\section{Professional development committees (PDC) or staff development committees (SDC)} are two versions of ongoing working groups that present opportunities for growth and serve library administrations as communication tools to promote and explain new initiatives, and that demonstrate a commitment to the professional growth of all staff. In his article, "Making the Case for In-house Training," Michael A. Crumpton argues that "Training should be seen as an investment in the organization's strategic plans and internal training should be seen as an investment in the current workforce." 2 The programming offered by these groups may have a broad scope that includes hosted trainings and workshops focused on a variety of topics or may be more narrowly focused on a specific aspect of a library's work.

In "Developing Effective Professional Development Programs: A Case Study, Shu Guo writes that the Central Michigan University Libraries' PDC promotes and administers professional development programs within the library and distributes professional development funds to staff. Each year, the PDC provides myriad opportunities including programs around a theme, updates from staff who attended conferences and trainings, and lectures by outside speakers. The methods of transmission include both in-person sessions as well as a newsletter that shares information with all staff.

PDCs may also be designed for a specific group within a library. As Lisa Shamchuk describes in "Professional Development on a Budget: Facilitating Learning Opportunities for Information Literacy Instructors," staff at MacEwan University in Edmonton, Alberta, organized a PDC to support library instruction. MacEwan staff established a community of practice that ". . . provides opportunities to share information, expertise, and insight by acting as a venue for communication, learning, mentoring, and self-reflection." ${ }^{3}$ Programming has included one-time workshops on teaching styles, and recurring opportunities to observe each other and learn new teaching methods. The MacEwan University PDC also presents workshops that invite all library staff and librarians from local institutions to participate. 
While examples of in-house professional development such as these are common within the library literature, no corresponding wealth of articles exists within archival literature. The archival literature primarily addresses grant-funded trainings, graduatelevel education, and professional certification. This focus on professionally organized and presented professional development is also evident at conferences. For example, at the Mid-Atlantic Regional Archives Conference (MARAC) spring 2016 meeting in Pittsburgh, a session titled "A Great Debate: Should Archivists Be Required to Take Continuing Education Courses?" presented a spirited exchange around the idea of the profession requiring continuing education. The topic that did not come up during this debate was in-house professional development as a way to promote continuing education in a cost-efficient and more institutionally tailored capacity.

Although not well represented in the archival literature, it is likely that in-house professional development opportunities occur at individual institutions by engaged colleagues and managers. For example, the 2016 Society of American Archivists annual meeting in Atlanta included a session titled "Into the Scrum: Applying Agile Project Management to Archival Processing” where presenter Matt Francis, associate head, Special Collections Library, Penn State University, discussed all-hands-on-deck processing initiatives. ${ }^{5}$ He also described monthly staff discussions as a way to provide professional development opportunities. Although not the topic of his talk or of the session, opportunities for staff discussion had relevance to the concept of the Agile process model he presented. Collaborative group discussions that focus on meeting the needs of an organization is the framework within which GW undertook this staff development project.

\section{Background}

Factors within the GW Libraries as well as within the SCRC fostered the decision to pursue an in-house professional development option for the staff. External factors included hiring a new dean of libraries and several new senior-level administrators, a renewed emphasis within the library to recognize staff members with skills underutilized in their current work assignments, a commitment to support and encourage cross-departmental collaborations, as well as budgetary constraints that reduced the funding available for travel and training. One of the new senior-level administrators was directly responsible for managing all specialized collections within the library including the SCRC. This managerial change along with the strengthened library-wide focus on collaboration influenced the decision to pursue an in-house training within the SCRC.

In 2014, the library hired a new associate university librarian (AUL) who assumed the managerial oversight of the SCRC. She brought fresh observations about current collection development procedures and posed questions designed to challenge the SCRC's existing practices and current staffing models. She wanted the collection development practices to be transparent to both the scholarly community and the library development officers. Specifically, she requested that SCRC staff post collection development policies on the library website to communicate why the SCRC collects, what the SCRC collects, and how the SCRC collects. 
In December 2014, the manuscripts librarian, curator of the Washingtoniana collection, ${ }^{6}$ was in the midst of a year-long project rewriting the SCRC collection development policy for this area. As part of the work for this rewrite, she reviewed the current policy, surveyed the SCRC collection for strengths and gaps, surveyed other local institutions with District of Columbia history holdings, ${ }^{7}$ and engaged in a comprehensive literature review of articles related to appraisal theory and collection development policies. ${ }^{8}$ This review includes articles on theory and practice, as well as historical overviews of appraisal and the construction of collection development policies related especially to why archivists collect and what archivists collect. The articles also discuss the historic marginalization of segments of society and how biases must be part of any discussion of policies.

The AUL, recognizing the manuscripts librarian's level of engagement and enthusiasm for this project, asked her to design a reading series for the department related to collection development. By inviting the manuscripts librarian to design the series, the AUL both acknowledged the significance of this work and identified its broader application and value for other SCRC staff. The AUL outlined a broad mandate, but gave the manuscripts librarian complete freedom to design the series' structure and elements. The AUL and manuscripts librarian agreed that all SCRC staff should participate, meaning both staff with collecting responsibilities as well as staff within related units such as reference and digital services.

The manuscripts librarian also invited several librarians from other departments with collection building responsibilities that overlap with the SCRC. By including nonSCRC staff, the series provided the opportunity to explore the similarities and differences between collection development for Special Collections and building collections of monographs, databases, and journals that comprise the library's core collections outside the SCRC.

To demonstrate the importance of this series and give it prominence in the work of the SCRC, the AUL wrote a departmental goal that included the series and also connected it to the Library Vision Statement's Objective \#5, to "Build robust and unique specialized collections to attract world class researchers." The SCRC departmental goal reads:

To enhance our existing collections and collecting activities, Special Collections and Archives members will:

- Participate actively in a collection development reading / discussion group, to begin in September 2015 and consisting of four selected readings on topics including: appraisal theory; mechanics of collection development policies; institutional resources and collecting; and reappraisal.

- Share and collectively review all existing departmental collection development statements; refine, redraw, or retire them as needed. Create collection development statements for collecting areas where there are none. 
- Post all reviewed collecting statements online so that our collecting activities are transparent to donors, users, and other collecting repositories.

Having participation as a goal with measurable objectives for all staff ensured a high level of support, but the ultimate success of the series would turn largely on its design and implementation.

\section{Design}

Envisioning a series of meetings during which staff read and discussed materials about collection development practice and theory, the manuscripts librarian began reviewing articles looking specifically for strong, thought-provoking elements likely to prompt lively and engaging discussion. While the expansive nature of the topic allowed for flexibility in choosing the articles, this breadth also proved challenging. The manuscripts librarian considered a significant number of articles, but with a limited number of sessions, the overall series structure could support only a small number of them.

Originally, the series was built around the four-part structure of Terry Cook's article "Evidence, Memory, Identity and Community: Four Shifting Archival Paradigms." This article presents a historical survey of the archivist as collection builder and includes a philosophical discussion of appraisal theory. Using Cook's article to articulate the shifting identity of the archivist provided all participants with a common frame of reference. The design called for six discussions. The first considered an in-depth reading of the Cook article; with each of the next four discussions focused on one of Cook's archival identity paradigms and a reading that spoke directly to it. The final discussion centered on the practical aspects of moving the SCRC's collection development practices forward.

The manuscripts librarian planned to lead each session and provide participants a list of potential discussion questions in advance. As work progressed, she realized that delaying a discussion about the practical application of the theories and ideas being discussed until the final session would minimize the series' impact on the work of the SCRC. Furthermore, if she was the sole discussion leader, an opportunity to provide other staff with leadership experience would be missed and the series would fail to take advantage of skills and strengths held by others within the SCRC. Therefore, the series was revised to share leadership and include a practical component in every session.

The final design called for four sessions, one scheduled per month, from September 2015 through December 2015, each with a different leader. The introductory e-mail to staff provided the series' description and outlined the following four objectives: 1) by June 30, 2016, the end of GW's fiscal year, all main collecting areas will post online a revised, or in some cases, a newly written collection development policy; 2) through discussions in the series sessions, the SCRC will draft a collection development policy template to include an agreed-upon set of common elements to be required for all policies; 3) the series will provide time to discuss the theories that inform SCRC practice; 
and 4) the series will provide all SCRC staff the opportunity to sit together and learn about each member's role in collection development.

\section{Implementation}

The article assigned for the first session was Terry Cook's "Evidence, Memory, Identity and Community: Four Shifting Archival Paradigms." The depth and breadth of Cook's article introduced, for those participants without an archives background, the seminal theories and archivists that shaped and continue to guide the field's work, while for others, the article presented an opportunity to reflect upon and reconsider work they have been doing for many years.

The first discussion included 15 participants from two departments within the library with the labor archivist as the lead. As the SCRC's most senior archivist, he added personal insight during the Cook discussion. The non-SCRC staff who participated provided further insight about library collection development theory and practice resulting in a recognition of the commonalities among all the collection development taking place throughout the library.

Sixteen people from three departments across the library, including all first session attendees participated in the second session. Attendees read and discussed, "At the 'rim of creative dissatisfaction': Archivists and Acquisition Development" ${ }^{10}$ by Timothy L. Ericson. Discussion followed Ericson's model of applying appraisal techniques to answer the question "Why am I saving this?" and using collection development policies to answer "Why am $\boldsymbol{I}$ saving this?" 11

For the practical component, each participant was asked to bring and share a collection development policy from another institution thought to have elements worthy of emulation. ${ }^{12}$ The variety of policies sparked an interesting discussion about elements that should be included in a well-crafted collection development policy and provided those staff without direct collecting responsibilities the opportunity to explain what they saw as necessary elements to assist their postcollecting work. The discussion lead for this session was a nonlibrarian with more than seven years of experience working primarily in technical services and reference. By his own account, this staff member does not speak often at meetings. Nonetheless, he agreed to lead the session and reported afterward that he appreciated the opportunity and felt a sense of accomplishment.

The third session had 14 participants from three library departments, all returning attendees. It focused on identifying the SCRC's stakeholders and their roles in the selection process and explored tools to address stakeholder concerns. The essay discussed, Alice D. Schreyer's "Elective Affinities Private Collectors \& Special Collections in Libraries,"13 examines the building of rare book libraries and traces the history of some of the most respected rare book collections in the country while exploring the influence rare book collectors have on libraries. Schreyer includes a list of 15 questions she suggests the library should ask about every potential donation. Part of the session explored 
how the SCRC might use this list in concert with its collection development policies when making decisions about acquiring specific donations. The curator of the Kiev Judaica and Hebraica rare book collection led the discussion. He augmented Schreyer's essay with his experience with the Kiev collection and his work with other substantial and renowned rare book collections at other institutions.

The fourth and final session included 14 attendees from three departments. The SCRC's National Educational Association (NEA) project archivist led the discussion, focusing on finalizing the policy template and discussing the SCRC's role as steward both of acquired content and of library and university resources. The group read Mark Greene's article "I've Deaccessioned and Lived to Tell about It: Confessions of an Unrepentant Reappraiser," ${ }^{14}$ which considers reappraisal as a collection development tool. The NEA project archivist provided SAA's "Guidelines for Reappraisal and Deaccessioning" 15 as a supplemental reading.

In this session, participants planned to finalize the collection development policy template, but the discussion revealed that not all participants had completed their individual policies and therefore were not ready to agree upon a final template. During a subsequent working meeting to finish the template, participants realized that some of the elements staff recommended were more appropriate for a collection management policy. None of the discussions had mentioned the differences between a collection management policy and a collection development policy.

In retrospect, the second session should have included some discussion about these differences. The SCRC does not have a collection management policy and as a group decided to write such a policy as a follow-up project. At this time, the SCRC has a collection management policy draft in revision and will post it on the SCRC website when completed.

\section{Evaluation}

After the discussion series concluded, the manuscripts librarian reviewed her aftersession notes and invited all participants to respond to a survey that focused on three main areas: 1) the mechanics of the series including the practical/theoretical framework for each session and the rotation of the discussion lead; 2) the relevance of the series to each participant's own assignment as well as the work of the department as a whole; and 3) the potential for future in-house professional development experiences.

The survey asked several questions related to the success of the mix of practical and theoretical elements. One respondent acknowledged that practical success would be realized only when staff take the ideas generated in the discussions and use them to craft collection development and management policies. Of the assigned articles, only the Cook article received criticism. Several staff did not like focusing heavily on theory and found it challenging to read without an extensive background in archival theory. It is important to note that the session with the Cook article was the only one without a 
practical discussion element. Consequently, it may have been more difficult to recognize the link between practice and theory. This supports the idea that including practical components in each session was an essential element of the series' success.

The survey respondents appreciated the rotation of leadership and recognized that this brought in diverse views and leadership styles. One lead used a seminar approach, providing an outline that summarized the reading, while another mirrored the model in the essay by presenting a historic overview of rare book library collection building. The other two discussion leads provided questions in advance and led discussions of the articles on a point-by-point basis. In addition, having leaders from a variety of professional levels demonstrated to all staff members that they have a voice in the work of the department, and most respondents who did not lead a discussion in this series expressed interest in serving in that role in the future.

Most respondents understood the relevance of the series partly because it was a departmental goal. However, respondents also recognized the series as significant to the work in the SCRC. The staff members without formal collecting responsibilities, including a nonlibrarian who now saw her work prescreening materials as an important role along the appraisal continuum, responded positively that the series provided added value to their work. The digital services librarian underscored the series relevance beyond the practical collection development policy drafting when she wrote: "The discussion series was both a learning opportunity and a communication opportunity. Because I have always worked with a different 'policy stack' (so to speak) it was interesting to approach each discussion's topic from the perspective of digital materials and the standard policies regarding digital materials, collection development, and preservation." ${ }^{6}$ Though only one respondent did not see the relevance of the archival literature readings to his work as a rare book curator, this is a significant observation to note as the SCRC works to explain to colleagues outside of the SCRC the relationship of its collection building to their efforts.

Most respondents thought the series assisted the SCRC in reaching a shared understanding of the structure of SCRC policies and the benefits of having a common perspective. One response effectively summarized the connection of practical work with theory. "It certainly seems like the more practical and specific business of declaring which items we'll accept or keep and which ones we'll decline is best informed by considerations of underlying purpose and responsibilities." ${ }^{17}$

In response to a survey question asking for suggestions of topics and outcomes for future in-house professional development, participants indicated an enthusiasm for this type of activity in the department, and several had suggestions for future topics. Those participants without archival training expressed the value of learning about the work of the archivist. One participant's comments revealed an added benefit when he described the series as "the equivalent of team building exercises of the mind." 18 


\section{Outcomes}

Prior to beginning the series, the curatorial areas including University Archives, Labor History, Education, and the Kiev Judaica rare book collection had collection development policies written or revised in 2007 and not reviewed since. Only the Washingtoniana collection policy was under active review. By June 2016, collection policies for all these areas had been revised using the template produced as a practical goal of the series and posted on the SCRC website. ${ }^{19}$ These curatorial areas, with dedicated curators, account for approximately 90 percent of all SCRC collections. The remaining 10 percent are from collecting areas that are nominally active, but do not have an assigned curator. To fully complete the discussion series goal, the policies for these collecting areas must be reviewed and rewritten using the template and posted online. This work has yet to be accomplished.

Soon after the discussion series ended, several additional in-house opportunities were launched. In one instance, the SCRC series was the direct inspiration for a similar project. A non-SCRC librarian series participant used this model to design her own discussion series. Her series focused on reading and discussing within the broad topic of digital literacy with the practical outcome that all participants would, in teams, write articles to submit for publication. The series sought to build an in-house capacity for mentoring and supporting scholarly pursuits.

The SCRC public services and outreach librarian held a discussion series about using primary sources within library instruction for all instruction librarians. A library-wide series, Madskillz, organized by the director of communications and outreach and a research and user services librarian, served as a way for staff to share conference presentations or present tools useful in their work. Finally, two SCRC staff implemented a less formal type of knowledge sharing: monthly unstructured gatherings focused on topics of interest and open to all library staff.

The discussion series also promoted other less easily documented, but no less significant successes. All SCRC staff now share a common understanding about the ways collection development fits into the work of the SCRC, the library, and, most broadly, the work of archivists. These discussions reinforced the idea that collection development thrives on collaboration.

For example, one important collaborative outcome is the partnership between the public services and outreach librarian and the manuscripts librarian. In her unique position as SCRC instruction and reference lead, the public services and outreach librarian has the opportunity to identify gaps in holdings. Recognizing these gaps, she will at times suggest donors to approach and content to purchase from vendors. Her input has enhanced active collection building. In addition, the manuscripts librarian will consult with the public services and outreach librarian on the teaching value of potential donations and consider this in her appraisal decisions. The discussion series allowed this partnership to emerge and flourish. 
Finally, the series strove to achieve an enhanced experience of collaboration and collegiality. Informal comments by staff and their responses on the survey indicate that this goal was achieved. Most SCRC staff attended all four discussions, and half the participants completed the survey and responded positively to holding future series.

\section{Conclusion}

Carried out in an academic library within a large university system, the series thrived in a setting that included numerous engaged colleagues, support from the senior library leadership, and a library-wide commitment to making professional development available for all staff. In this context, in-house, staff-led professional development is a powerful model with few budgetary limitations. However, it does require time to design and considerable effort from participants. Therefore, it is probably limited in the number of times it can be used in an academic year.

The design of this series around a framework of archival thought and history, however, makes it well suited for adaptation by other types of archival institutions, from lone arrangers to small archives with few staff. Because the series stressed the collaborative nature of the work archivists do, a lone arranger could develop a similar series with other lone arrangers within a geographic area or online and take full advantage of the expertise and varied years of experience among professional colleagues. Smaller archival institutions, such as college archives, may find it useful to reach beyond their library systems and include personnel from other schools to broaden the academic disciplines included. While the theoretical discussion will work in any setting, the practical elements, if included, would have to be written to benefit colleagues from various institutions with different collecting mandates and processes.

All of the goals from the SCRC in-house professional development series-the practical, the participatory, and the aspirational-presented opportunities for staff to share their expertise and learn from each other. The series successes and the continued initiatives within the library demonstrate that this model provides for professional growth and workplace team building. The GW libraries and the SCRC look forward to continuing to develop these opportunities for all staff.

\section{ABOUT THE AUTHOR}

Jennifer King is the collections coordinator and manuscripts librarian in the Special Collections Research Center at The George Washington University. In this position, she curates the Washingtoniana collection, manages technical services for the department, and supervises the archivists responsible for curating two of the major collecting areas in Special Collections: the Labor History Research Center and the National Education Association Archives. King has an MLS with an archival concentration from the University of Michigan and has worked in both university and public library settings. 


\section{NOTES}

1. Ann MacKay Snowman, "Leading Staff Development from the Bottom Up," Pennsylvania Libraries: Research E Practice 5, no. 1 (2017): 11.

2. Michael A. Crumpton, "Making the Case for In-house Training," The Bottom Line: Managing Library Finances 24, no. 3 (2011): 172.

3. Lisa Shamchuk, "Professional Development on a Budget: Facilitating Learning Opportunities for Information Literacy Instructors," Partnership: The Canadian Journal of Library and Information Practices and Research 10, no. 1 (2015): 2.

4. Eric Cartier, Blake Relle, and Christine Anne George, "A Great Debate: Should Archivists Be Required to Take Continuing Education Courses?," debate at the Mid-Atlantic Regional Archives Conference (MARAC) spring meeting, Pittsburgh, PA, April 2016.

5. Matt Francis, "Based on a True Story: Agile Inspired Collections Work at Penn State," PowerPoint presentation, part of session 609 "Into the Scrum: Applying Agile Project Management to Archival Processing," Council of State Archivists and the Society of American Archivists meeting, Atlanta, GA, August 2016.

6. The author has served as the curator of the Washingtoniana collection since 2003. She is responsible for building a collection that documents the history of the District of Columbia. She works closely with two other institutions in the district, the DC Public Library and the Historical Society of Washington, DC, to build as comprehensive a collection for DC history as possible.

7. The review included 78 local institutions including museums, libraries, universities, historical societies, and community archives. For each institution, the data captured included a brief description; the collecting scope as it related to Washington, DC, history; and access information.

8. For a sample list of the articles the manuscripts librarian read for her review, please see the selected bibliography at https://scholarspace.library.gwu.edu/downloads/vh53wv79n.

9. Terry Cook, "Evidence, Memory, Identity and Community: Four Shifting Archival Paradigms," Archival Science 13, nos. 2-3 (2013): 95-120.

10. Timothy L. Ericson, "At the 'rim of creative dissatisfaction': Archivists and Acquisition Development," Archivaria 33 (1991-92): 66-77.

11. Ibid., 68 .

12. The collection development policies included among others the Earl K. Long Library Louisiana and Special Collection Development Policy, http://libguides.uno.edu/ld.php?content_id=17234318; the University of New Orleans; Emory University Digital Collection Development and Preservation Policy, 2015, http://guides.main.library.emory.edu/ld.php?content_id=6155258; Yale Libraries Collections Development Policy, http://web.library.yale.edu/mssa/offices/collection-development/ policy-list; Carleton College Gould Library Special Collections "Philosophy and Purpose," https:// apps.carleton.edu/campus/library/special_collections/philo/.

13. Alice D. Schreyer, Elective Affinities Private Collectors \& Special Collections in Libraries (Chicago: The University of Chicago Library, 2001).

14. Mark A. Greene, "I've Deaccessioned and Lived to Tell about It: Confessions of an Unrepentant Reappraiser," Archival Issues 30, no. 1 (2006): 7-22.

15. The Society of American Archivists, Reappraisal and Deaccessioning Development and Review Team, revised Technical Subcommittee on Guidelines for Reappraisal and Deaccessioning, "Guidelines for Reappraisal and Deaccessioning" (2017), https://www2.archivists.org/sites/all/ files/GuidelinesForReappraisalDeaccessioning_2017.pdf.

16. Jennifer King, "Survey of Collection Development Discussion Series," survey distributed electronically on February 1, 2016.

17. Ibid.

18. Ibid.

19. The collection development policies are on the SCRC website, https://library.gwu.edu/scrc/collections/colldev. 